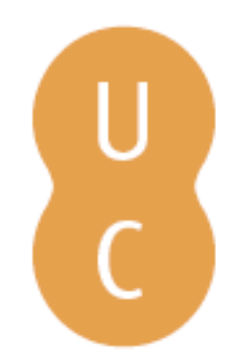

\title{
pommalina
}

\section{Recorrido generativo de las comedias de Terencio: de la traducción filológica al texto espectacular}
Autor(es):
Pianacci, Rómulo
Publicado por: Imprensa da Universidade de Coimbra; Annablume
URL
persistente:
URI:http://hdl.handle.net/10316.2/40921
DOI:
DOI:https://doi.org/10.14195/978-989-26-1298-0_15
Accessed : $\quad$ 26-Apr-2023 04:35:07

A navegação consulta e descarregamento dos títulos inseridos nas Bibliotecas Digitais UC Digitalis, UC Pombalina e UC Impactum, pressupõem a aceitação plena e sem reservas dos Termos e Condições de Uso destas Bibliotecas Digitais, disponíveis em https://digitalis.uc.pt/pt-pt/termos.

Conforme exposto nos referidos Termos e Condições de Uso, o descarregamento de títulos de acesso restrito requer uma licença válida de autorização devendo o utilizador aceder ao(s) documento(s) a partir de um endereço de IP da instituição detentora da supramencionada licença.

Ao utilizador é apenas permitido o descarregamento para uso pessoal, pelo que o emprego do(s) título(s) descarregado(s) para outro fim, designadamente comercial, carece de autorização do respetivo autor ou editor da obra.

Na medida em que todas as obras da UC Digitalis se encontram protegidas pelo Código do Direito de Autor e Direitos Conexos e demais legislação aplicável, toda a cópia, parcial ou total, deste documento, nos casos em que é legalmente admitida, deverá conter ou fazer-se acompanhar por este aviso.

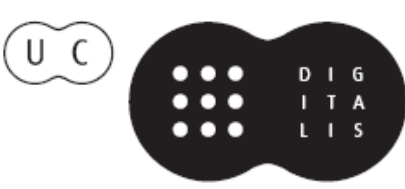




\section{O Livro do Tempo: \\ Escritas e reescritas}

\section{Teatro Greco-Latino e sua recepção II}

Maria de Fátima Silva, Maria do Céu

Fialho \& José Luís Brandão (coords.)

IMPRENSA DA UNIVERSIDADE DE COIMBRA 


\title{
Recorrido generativo de las Comedias de Terencio:
}

DE LA TRADUCCIÓN FILOLÓGICA AL TEXTO ESPECTACULAR (About the genesis of Terentius' comedies: from a philological translation to a performative text)

\author{
Rómulo Pianacci (rpianacci@gmail.com) \\ UNMdP y UNCPBA
}

\begin{abstract}
Resumen - Si la actualidad es uno los rasgos que caracterizan a "los clásicos", posiblemente esta actualidad esté directamente vinculada a la lectura, apropiación, y por lógica consecuencia, a la traducción que cada generación hace de los mismos. La representación de un texto clásico debería servir para hacerlo dialogar con nosotros, tendiendo a una comunicación fluida, que sólo puede suceder cuando no se menosprecia, ignora o traiciona ni lo clásico ni lo contemporáneo. Pero, ¿cómo lograrlo? La respuesta no es simple. De la experiencia se nutre el presente trabajo.

Palabras clave - Comedia, Plauto, Terencio, transducción, puesta en escena.
\end{abstract}

Aвstract - If enforcement is one of the features that characterizes "The Classics", possibly today this aspect is directly related to the reading, appropriation, and in logical consequence, to the translation that each generation makes of them. The representation of a classic text should serve to make it dialogue with us, tending to a fluid communication, that can only happen when not it belittles, ignore or betray neither classical nor contemporary matters. But how to achieve this? The answer is not simple. The present work is based on experience.

Keywords - Comedy, Plautus, Terence, transduction, staging.

\section{INTRODUCCIÓN}

Esta comunicación discurre acerca de diversos modos cómo se ponen en escena hoy en día las obras de teatro clásico grecolatino, y la experiencia concreta de llevar a escena La ollita de Plauto en el marco del Congreso CLASTEA, que tuviera lugar en Mar del Plata del 23 al 27 de agosto de 2011; como así también la presentación del Proyecto UBACyT 2011-2014 Recorrido generativo de dos comedias de Terencio: de la traducción filológica al texto espectacular y puesta en escena, que dirige la Dra. Marcela Suárez con un grupo de colaboradores ${ }^{1}$.

Las diferentes posturas sostenidas apasionadamente por filólogos, actores, dramaturgistas, directores y funcionarios estatales, intentan delimitar quién

${ }^{1}$ Así también la presentación del Proyecto UBACyT 2011-2014 Recorrido generativo de dos comedias de Terencio: de la traducción filológica al texto espectacular y puesta en escena, que dirige la Dra. Marcela Suárez con un grupo de colaboradores. 
debe decidir acerca de cómo hacer la traducción, o mejor dicho transducción, adaptación o versión de una obra clásica.

La primera cuestión a tener en cuenta es que la información de que dispone el espectador actual ya no es la misma, el mundo y la manera de contar las historias han cambiado mucho desde el momento en que esos textos fueran escritos.

$\mathrm{Si}$ el objetivo es entretener y trasmitir un mensaje, es prioritario que el destinatario lo pueda leer o decodificar y que el material le resulte lo más cercano posible, sin contrahacerlo o deformarlo. Consecuentemente, la polémica filólogos vs. teatristas o guionistas pareciera no tener fin.

Actualizar este debate y determinar -si fuera posible- cuál es el límite en la manipulación de este material o cómo fijarlo, es lo que se propone aquí a fin de guiar tanto en la creación como en la producción de los profesionales, como así también para los docentes y estudiantes.

\section{UNA POLÉMICA QUE CONTINÚA}

Juanjo Guerenabarena en su artículo Adaptar... verter, traducir, matar recoge las opiniones certeras de Domingo Miras, Ignacio del Moral, Jesús Campos, Rafael Pérez Sierra y Domingo Ynduráin al respecto de estas cuestiones. El primero opina que cuando se pone en escena un texto clásico basta un pequeño toque o restauración, que pareciera claro que debe hacerlo un creador y no un filólogo: "El filólogo suele tener preferencia por elementos de detalle o de lenguaje, que no son fundamentales en la adaptación del teatro" (Guerenabarena 1988: 8). A esta opinión se le suma Ignacio del Moral, que sostiene que el trabajo del filólogo, en caso de darse, debe ser previo a la adaptación (Guerenabarena 1988: 7).

Por su parte, en la misma mesa redonda de la cual da cuenta el citado artículo, frente a la inevitabilidad de las adaptaciones sostenida por algunos de los participantes, Miras finalmente termina reconociendo (Guerenabarena 1988: 8):

Lo ideal sería que no hicieran falta las adaptaciones. Prefiero no adaptar. Sin embargo, he aceptado trabajos de este tipo, pero los he realizado como un servidor del autor, retocando lo menos posible, intentando pasar desapercibido. Esta creo que es una diferencia entre el que hace una adaptación y el que hace una versión: el versionista quiere manifestarse; el adaptador, no.

Rafael Pérez Sierra (Guerenabarena 1988: 9) prefiere utilizar la palabra "restauración” y justifica su elección:

Soy partidario de restaurar, no de recrear, aunque respeto la recreación. Entiendo la restauración en términos casi pictóricos, poniéndome siempre en la 
época de la que se trata y sin perder de vista el Diccionario de Autoridades. Me someto a la disciplina de ser fiel al sentido que las palabras cuando fueron escritas.

Respecto de las puestas transducidas a otra época o contexto, Domingo Ynduráin (Guerenabarena 1988: 14) acotaba:

De tal manera que estas propuestas de mantener el argumento, la historia, pero cambiar la forma, son absolutamente lícitas, pero no si se quiere hacer una obra clásica. Estamos volviendo a un ahistoricismo absolutamente peligroso.

Desprendido el mito de todas sus circunstancias, la obra se torna patéticamente teleteatral y excesivamente pedestre.

Frente a este panorama es que Jesús Campos (Guerenabarena 1988: 9) no quiere entrar en la polémica de cómo hacer algo que no está demostrado que se tenga que hacer, al considerar que del hecho teatral del pasado sólo queda la propuesta textual. El resto de los componentes de la fórmula han desaparecido para siempre. Justifica esta afirmación por el hecho que aquello con los que los textos se complementaban para conformar el todo que es hecho teatral se han perdido y cualquier intento de reinventarlos es emparchar o remendar. Para Campos, hoy vivimos un teatro de directores, donde la manipulación es considerada un valor positivo, resultando así productos híbridos, de poca significación aunque muy adecuados para contribuir a la confusión cultural.

En general, los partidarios de la necesidad del rescate del Teatro Clásico, si bien reconocen que no se puede "reproducirlo", sí acuerdan en que se puede recrearlos. Por ejemplo no cualquier texto del siglo XVII puede tener interés hoy en día, y es por esta razón que cuando fuera director de la Compañía Nacional de Teatro Clásico, Adolfo Marsillach (Guerenabarena 1988: 9) opinaba:

Nosotros creemos que hay un camino intermedio, que es el que ahora estamos recorriendo: encontrar unos textos no demasiado transitados, sin renunciar a los "grandes" títulos. Es decir, no caer en el aburrimiento o la comodidad de hacer siempre las mismas obras ni en el prurito investigador del descubrimiento por el descubrimiento. La necesidad de un repertorio nos parece obvia. Sólo una Comedia Nacional puede permitirse económicamente esa posibilidad.

La variedad de lecturas contemporáneas abarca desde el respeto estricto del texto original, al teatro de títeres, el musical, el teatro de zancos, espectáculos de calle o propuestas de teatro alternativo u off. Esto viene a demostrar una vez más la permanente vigencia de estos textos, y si bien los resultados son desparejos y muchas veces cuestionables, es importante destacar la recurrencia de los creadores a abrevar de la fuente tan rica que nos brinda la Tradición. 


\section{El postergado Terencio}

En las representaciones de teatro grecolatino llevadas a cabo en Iberoamérica y en Europa en los últimos años, se puede advertir un claro predominio de la comedia plautina y una aparición esporádica de las de Terencio, presente, no por casualidad, con una única obra: El eunuco.

Una rápida revisión de los programas de la Asociación de Festivales de Teatro Grecolatino PROSOPON puntualiza que dicha obra ha sido representada en tres oportunidades: la primera en el año 2008 en el Teatro Romano de Mérida por el Grupo Siberia Extremeña de Talarrubia, Badajoz; la segunda en el mismo teatro dos años más tarde por el Grupo Calatalifa de Odón y finalmente, la tercera, también en 2010, en el Auditorio del Palacio de Congresos de Huesca, Zaragoza, por el Grupo Calatalifa de Madrid $^{2}$.

La escasa presencia del corpus terenciano en los escenarios del mundo está probablemente vinculada a la falta de publicación y difusión de sus comedias $y$, particularmente, en la inexistencia de versiones aptas para ser representadas. Esto sucede pese a la publicación en 1966 del trabajo de A. Marquerie, que incluye la versión "representable" de una de ellas: Formión.

Al referirse a Terencio, este autor afirma (1966: 34):

Terencio no respetó la comedia original griega, y, con el mismo criterio, nosotros nos hemos tomado la libertad en esta Versión representable, no erudita, viva y no disecada, de imprimir un ritmo más rápido en algunas ocasiones a la acción, repartir o redondear frases y réplicas y efectuar algunas alteraciones y transposiciones en el diálogo, con esa ambición, tantas veces expuesta en estas líneas, de hacerlo más comprensible y asequible a nuestro público. Sin embargo, conservamos siempre e íntegramente todos los valores y propósitos de la pieza inicial sin suprimir ninguno, respetamos la exposición, el nudo, el desenlace, los cambios de acción y lugar y, por supuesto, la unidad de tiempo.

Convendría recordar que Terencio no fue un traductor, sino que escribió sus propias comedias tomando como hipotexto la comedia griega. La lectura de la obra de Marquerie, su confusión en torno a los conceptos de autor y traductor y esta suerte de olvido que se han ejercido sobre el africano, son los factores que han impulsado a plantear, en el marco del Proyecto UBACyT 2011-2014 citado, el recorrido generativo de las comedias de Terencio; que se inicia con la traducción filológica y concluirá con la publicación del texto espectacular y la posterior puesta en escena ${ }^{3}$.

${ }^{2}$ Estrenada en el Festival de Teatro Clásico de Mérida en 2014, en forma de teatro musical. Reestrenada en el Teatro de La Latina de Madrid en 2015, se anunció que volvería a presentarse en Mérida en 2016.

${ }^{3}$ La primera etapa sólo estará dedicada a Adelphoe y Phormio, porque presentan una 
El procedimiento nuclear del proyecto consiste en la confrontación y problematización de los distintos tipos de traducción de la comedia que pueden llevarse a cabo según las diversas formas de recepción contemporáneas de las mismas, a saber: la lectura y el espectáculo teatral.

Como afirma Botton-Burlá (1994: 332): "los procesos básicos que se encuentran implicados en todo acto de traducción son dos: la comprensión del texto original y su formulación en la lengua meta". Cuando el texto que está en juego es un texto clásico latino, esta tarea correspondería a los filólogos, que disponen de las herramientas necesarias para hacer que la vida de la obra continúe, como lo expresa Benjamin (1961: 71). En efecto, los problemas que implica el trabajo con un texto escrito dos siglos antes de Cristo en lengua latina requieren de un minucioso trabajo filológico que permita fijar el texto y lograr una traducción que, además de las cuestiones estrictamente lingüísticas y estilísticas (elección entre el verso y la prosa, cuestiones sintácticas, cuestiones léxicas), favorezca la comprensión de la dimensión semántica, que pone en juego no solamente la pluralidad de sentidos que de por sí la lengua abre; sino también las referencias culturales (mitológicas, históricas, sociales, intertextuales), muchas veces fuera del alcance del espectador contemporáneo.

Sin embargo, un texto espectacular supone otras dimensiones más que el texto escrito: la representación y la ejecución. En esta instancia, no es posible echar mano a ciertos recursos paratextuales que el texto impreso pone en práctica, como por ejemplo las notas al pie. Por esta razón, se vuelve imprescindible el trabajo conjunto del director teatral con los filólogos, de manera que pueda lograrse un texto que al ser puesto en escena permita acceder a su significado pleno. ¿Es esto posible? Está claro que una traducción total y perfecta no es posible; por el contrario, muchos especialistas en traducción literaria afirman que toda traducción es una re-creación e incluso Peter Newmark sostiene (2004: 234): "Cuando se pasa una obra de teatro de la cultura de la LO (Lengua Original) a la de la LT (Lengua Terminal) ya no es una traducción sino una adaptación".

En su Introducción a las actas del Congreso Internacional realizado en Murcia en noviembre de 1995, Ángel Luis Pujante (1996: 16) afirma que la traducción literaria es: "una reelaboración de obras nacidas en una cultura para que funcionen en una cultura receptora distinta y a veces muy distante en el espacio y en el tiempo; una reelaboración que se presta a la apropiación y a la manipulación.” Más adelante agrega que la reelaboración y manipulación parecen haberse dado más claramente en el teatro donde siempre se ha aspirado a la máxima libertad frente a los textos. Efectivamente, el filólogo debe apropiarse del texto para comprenderlo y hacerlo comprender al lector moderno. Pero, ¿qué significa

temática que resulta de interés para los lectores y el público teatral de nuestra época, y además han sido escasamente traducidas y llevadas a escena. 
manipulación? ¿Qué significa máxima libertad frente a los textos? Para que el texto sirva para realizar una representación teatral, debe superar las dificultades y distancias que le impiden al espectador moderno no especializado comprender la obra. Manipular el texto y hacer de el una versión libre, más contemporánea, permite quizá que el espíritu del texto original siga vivo, de acuerdo a las palabras de Benjamin, pero indudablemente impide que la obra permanezca, puesto que se tratará de otra totalmente distinta. ¿Cómo resolver entonces este dilema?

Conviene recordar nuevamente a Pujante (1996: 16-17), quien resume dos aspectos importantes de esta discusión. En primer lugar afirma: "Las traducciones filológicas del teatro clásico son y seguirán siendo necesarias, pero tendría que haber cada vez más traducciones solventes con una orientación teatral”. En segundo lugar: "El mundo académico debe abrirse más hacia la representación, pero también el mundo del teatro debe respetar las exigencias filológicas de los textos y evitar prácticas poco dignas, como, por ejemplo, la de realizar y utilizar versiones o adaptaciones que no son sino refritos de traducciones ya publicadas".

Andrés Pociña (2000: 160) considera que: "un texto real, auténtico tiene que ser al mismo tiempo representable, una traducción hecha para la escena, y esto es lo que casi nunca ofrecemos los filólogos". Una versión representable de una comedia antigua debería ser el producto de la labor conjunta entre el traductor y el director de teatro, fundada siempre en un pretexto o avant-texte: la traducción filológica.

Por todas estas razones, en una primera etapa, este Proyecto se propuso llevar a cabo una traducción filológica de tres comedias ${ }^{4}$, es decir, una versión para ser leída, lo más ajustada al original sin que ello vaya en detrimento de su calidad literaria y debidamente anotada. Para lo cual se recurrió al uso de ediciones eruditas del texto original de las cuales se tomaron las lectiones establecidas por el editor, a menos que sea necesario adoptar variantes del aparato crítico; cotejo de distintas traducciones en lengua hispana y extranjera pertinentes que enriquezcan las posibles interpretaciones del texto; estudio del corpus terenciano seleccionado en los planos fonético-métrico, morfológico, sintáctico, lexical, retórico y estilístico, análisis de conductas y pautas culturales, especialmente de aquellas relacionadas con el derecho romano y ático, indispensables para la contextualización y comprensión del significado original del texto; reflexión y debate en el seno del equipo sobre las variantes y posibilidades de traducción, para obtener un producto nutrido por distintas lecturas.

Partiendo de la traducción filológica, se abordó, en una segunda etapa, la elaboración del texto espectacular de las comedias.

Pero, ¿cómo lograrlo satisfactoriamente? La respuesta es y no es simple: sobre la base del trabajo conjunto de los filólogos y del director teatral y en virtud

\footnotetext{
${ }^{4}$ Los hermanos, Formión y El eunuco.
} 
de principios claros, tales como la problematización de las distintas posibilidades discursivas y de lengua que permitan la actualización de los elementos patéticos (comicidad - reflexión), la introducción de modificaciones en la estructura misma para adecuar las obras al público contemporáneo, la supresión del anacronismo, el respeto de los resortes intrínsecos de la comicidad del autor, la actualización a través de mecanismos que no distorsionen el espíritu ni transgredan las normas culturales de la época en que las comedias fueron escritas.

Finalmente, el Proyecto contempla reunir los tres textos, latín, traducción filológica y texto espectacular, en una publicación destinada tanto a los lectores especializados, como a teatristas y público en general.

\section{Casi a modo de Conclusiones}

¿Para qué hacer teatro clásico hoy en día? Con seguridad que no es para dar una clase de Literatura que ahuyente al público, ni para enseñarle los códigos internos que la rigen como las reglas de un juego o deporte. Quizás sirva para poder vivir mejor nuestro presente, no como rescate del ayer, sino para poder convivir con el pasado como pasado, y con las contradicciones de ambos, eliminando la sustancia muerta y el dogmatismo.

Frente a la disyuntiva "mundo de ayer / mundo de hoy", la adaptación de los textos clásicos surge como necesaria frente a la distancia histórica que nos separa de su contexto de producción, afirmándose como texto del presente "lo cual no excluye su negación o su sustitución como tal texto del pasado” según concluye Francisco Ruiz Ramón (1988: 25-32).

Más adelante agrega acertadamente:

Finalmente, reescribir un texto supone, en primer lugar, decir lo dicho, pero nunca lo no dicho en el original, pues la función de la adaptación no es inventar un texto nuevo, es decir un texto otro, sino hacerlo significar por relación al nuevo contexto cultural en el que el texto clásico va a realizar su sentido.

Si la deseada comunicación con el público no se produce, si el texto banaliza, aburre e indigesta a los espectadores, ¿para qué el esfuerzo, el tiempo y el dinero de montar un texto clásico? La representación de un texto clásico debería servir entonces para hacerlo dialogar con nosotros, tendiendo a una comunicación fluida, que sólo puede suceder cuando no se menosprecia, ignora o traiciona ni lo clásico ni lo contemporáneo. 


\section{Bibliografia}

Benjamin, W. (1969), "The task of the translator", in Illuminations, New York: Schocken Books, 71.

Botton-Burlá, F. (1994), "La traducción”, in Brunel, P., Chevrel, Y. (dir.), Compendio de Literatura Comparada. México: Siglo XXI, 329-346.

Guerenabarena, J. (1988), “Adaptar... verter, traducir, matar”, Boletín de la Compañia Nacional de Teatro Clásico 9: 7-15.

Marquerie, A. (1966), Versiones representables de teatro griego y latino. Madrid: Aguilar.

Newmark, P. (2004), Manual de traducción. Madrid: Cátedra.

López, A., Pociña, A. (2000), Estudios sobre la Comedia Romana. Frankfurt am Main: Peter Lang.

Pujante, A., Gregor, K. (eds.) (1996), Teatro clásico en traducción: texto, representación, recepción. Actas del Congreso Internacional, Murcia, 9-11 de noviembre, 1995. Murcia: Servicio de Publicaciones, Universidad.

Ruiz Ramón, F. (1988), "Sobre la adaptación de un texto clásico", in Celebración y Catarsis (Leer el Teatro Español) Cuadernos de la Cátedra de Teatro de la Universidad de Murcia No 13. Murcia: Universidad. 